\title{
Ruth Stawarz-Luginbühl, Les «Emblemata/Emblemes chrestiens» (1580-1581) de Théodore de Bèze: un recueil d'emblèmes humaniste et protestant
}

\section{Filippo Fonio}

\author{
(2) OpenEdition \\ Journals \\ Edizione digitale \\ URL: http://journals.openedition.org/studifrancesi/27458 \\ DOI: $10.4000 /$ studifrancesi.27458 \\ ISSN: 2421-5856

\section{Editore} \\ Rosenberg \& Sellier
}

\section{Edizione cartacea}

Data di pubblicazione: 31 décembre 2006

Paginazione: 593-594

ISSN: 0039-2944

\section{Notizia bibliografica digitale}

Filippo Fonio, «Ruth Stawarz-Luginbühl, Les «Emblemata/Emblemes chrestiens» (1580-1587) de

Théodore de Bèze: un recueil d'emblèmes humaniste et protestant », Studi Francesi [Online], 150 (L | III) |

2006, online dal 30 novembre 2015, consultato il 08 novembre 2020. URL : http://

journals.openedition.org/studifrancesi/27458; DOI : https://doi.org/10.4000/studifrancesi.27458

Questo documento è stato generato automaticamente il 8 novembre 2020.

\section{cc) $($ ) $\ominus$}

Studi Francesi è distribuita con Licenza Creative Commons Attribuzione - Non commerciale - Non opere derivate 4.0 Internazionale. 


\title{
Ruth Stawarz-Luginbühl, Les «Emblemata/Emblemes chrestiens» (1580-1581) de Théodore de Bèze: un recueil d'emblèmes humaniste et protestant
}

\author{
Filippo Fonio
}

\section{NOTIZIA}

RUTH STAWARZ-LUGINBÜHL, Les «Emblemata/Emblemes chrestiens» (1580-1581) de Théodore de Bèze: un recueil d'emblèmes humaniste et protestant, «Bibliothèque d'Humanisme et Renaissance», LXVII, 3 (2005), pp. 597-624.

1 La studiosa presenta un contributo incentrato sul rapporto fra testo e immagine nelle Icones, id est verae imagines... di Théodore de Bèze, edite nel 1580 in appendice agli Emblemata, e tradotte l'anno successivo da Simon Goulart (Quarante quatre emblemes chrestiens). L'opera, in cantiere dal dicembre 1577 come risulta dall'epistolario di Bèze, consta di quarantaquattro ritratti di uomini illustri, e conosce, congiuntamente agli Emblemata, un certo successo all'epoca (cinque edizioni vivente l'autore). La studiosa riprende in parte un articolo di Christophe Chazalon (BHR, LXVI, 2004), prendendo posizione in merito alla vexata quaestio dell'iconofilia di Bèze. Superando la funzione retorica che le immagini rivestono negli Emblemata, le Icones si presenterebbero come un progetto più esplicitamente agiografico, in cui la complementarità fra testo $\mathrm{e}$ immagine contribuisce ad aumentare l'incisività del messaggio esemplare. Pur in presenza di legami formali e tematici indiscutibili, è difficile individuare una struttura unitaria dell'opera, e ancor più difficile sostenere che si tratti di un 'edificio' mnemotecnico. Il didatticismo e la celebrazione dei martiri protestanti possono 
fungere così da chiave di lettura che suggerisce un certo grado di coesione nella forma aperta delle Icones, opera caratterizzata da forti legami con la tradizione del genere ma pure da un certo grado di autonomia. I martiri costituiscono per Bèze l'élite degli uomini illustri di cui si tratta nell'opera. 